\title{
Efeitos da (des)organização do tempo narrativo: a calma de Gustavo Fring e a cooperação do leitor
}

Wanderley Anchieta' http://orcid.org/0000-0003-0864-9288

Niterói $(\mathrm{RJ})$. Brasil

Resumo: O texto ocupa-se de estremar a noção de ordenamento cronológico naquilo em que se relaciona com a formulação da coerência narrativa. Então, mencionamos o crucial papel de cooperação do leitor na ressonância dos efeitos das estratégias das tramas. Utilizamos o referencial teórico advindo do estruturalismo narrativo, com contribuições importantes de autores como Umberto Eco, semioticista, e David Bordwell, cognitivista. Conjugamos o aporte das teorias com análise centrada num personagem, Gustavo Fring, naquilo em que um de seus traços de caracterização revela do arranjo dos tempos e das inferências possibilitadas ao longo do desenrolar de Breaking Bad.

Palavras-chave: narrativa; cooperação do leitor; ficção seriada.

Abstract: Effects of the (dis)organization of the narrative time: the calmness of Gustavo Fring and the cooperation of the reader - The paper focuses on defining the notion of chronological order, given its relation to the formulation of narrative coherence. Afterward, we mention the crucial role of e reader cooperation in resonating the effects of plot strategies. We base our theoretical references on narrative structuralism, with important contributions from authors such as Umberto Eco, semioticist, and David Bordwell, cognitivist. We combine the theoretical contributions with a character-centered analysis on Gustavo Fring, more specifically on how one of his characterization traits reveals the arrangement of the times and the inferences made possible throughout the unfolding of Breaking Bad.

Keywords: narrative; reader cooperation; serial fiction. 


\section{Introdução}

Narrativas conformam-se a si mesmas e, nessa conformação, delineiam seus tempos com intuito de gerar congruência entre causas e consequências, cuja resultante forme um todo harmonioso e chamativo. Elas informam seu próprio caminho de leitura, não obstante a pressão que o uso cotidiano e o arbítrio cultural faz delas.

Elas conclamam o leitor a reconstituir e discernir sua trama numa história inteligível que tenha potência estética. Sua força reside no grau de narratividade, definido por Meir Sternberg (1992, p. 529, tradução nossa) "como o jogo de suspense/curiosidade/surpresa entre o tempo representado e o comunicativo (em qualquer combinação, seja qual for o meio, qualquer manifestação ou forma latente)".

Tais efeitos, suspense ou curiosidade ou surpresa, são evocados a partir do envolvimento que o leitor se proponha a realizar na busca pela congruência. Umberto Eco nomeia esse envolvimento de cooperação, que interage como um jogo de aposta sobre o dito e também sobre o não dito. Por sua vez, essas apostas ou inferências fazem gravitar a empatia e despertam, no leitor que siga corretamente as pistas textuais, o impacto planejado pelo autor.

Neste trabalho, extrairemos um item de caracterização de um personagem de Breaking Bad, a saber, a calma de Gustavo Fring (Giancarlo Esposito), e comentaremos como ela representa uma estratégia de evocação emotiva que se desenrola no tempo do seriado.

\section{Força da narratividade, na desordem e na ordem}

Convém começar pelo começo. Mas, quiséramos nós que fosse tão simples. Isso uma vez que tal categoria narratológica - a da lógica e eficiência da localização do princípio das histórias - está sub judice constante para os pesquisadores da área. Por onde se deve começar uma narrativa? Dom Casmurro tem início no final, por exemplo. É quando Bentinho conta ao leitor que "(u)ma noite destas, vindo da cidade para o Engenho Novo, encontrei no trem da Central um rapaz aqui do bairro, que eu conheço de vista e de chapéu. Cumprimentou-me, sentou-se ao pé de mim, falou da Lua e dos ministros, e acabou recitando-me versos" (ASSIS, 1899, p. 1). Tal fato ocorre depois de toda a linha nevrálgica e emocional da história, quando um Bentinho de meia idade, rancoroso, rememora suas dores e dissabores vividos em relação ao amor de sua vida, Capitu. Já Budapeste, de Chico Buarque de Holanda (2016, p. 5), tem início no meio ou in media res: "Devia ser proibido debochar de quem se aventura em língua estrangeira. Certa manhã, ao deixar o metrô por engano numa estação azul igual à dela, com um nome semelhante à estação da casa dela, telefonei da rua e disse: aí estou chegando quase". Esse momento medial da história se passa quando José Costa, o protagonista, passa a viver como emigrante em Budapeste, onde se apaixona por Kriska e se torna conhecido 
por Kósta Zsoze. Em relação ao audiovisual, como esquecer de Touro Indomável (1980, EUA, dir.: Martin Scorsese) e sua memorável cena inicial em que um Jake LaMotta (Robert DeNiro), obeso e envelhecido, num camarim, recita a si próprio versos sobre suas antigas conquistas no boxe, às quais seremos apresentados logo em seguida. Ademais da marcante cena inaugural de Breaking Bad, em 2008, quando Walter White (Bryan Cranston) bate com seu veículo adentro do deserto e dele sai somente de cuecas, em desespero e com uma pistola na mão, mergulhado numa atmosfera sonora de múltiplas sirenes de carros de polícia. Exemplos haveria infinitos a seguir, contudo, sigamos na questão da lógica do começo para a narratologia.

Aristóteles assim escreveu em sua Poética': "a tragédia é imitação de uma acção completa, constituindo um todo [...] (que) é aquilo que tem princípio, meio e fim. 'Princípio' é o que não contém em si mesmo o que quer que siga necessariamente outra coisa [...] (mas) tem depois de si algo com que está ou estará necessariamente unido (§ 41 e 42 do capítulo VII, grifo nosso). O professor Meir Sternberg (1992, p. 481) explica que essa passagem da Poética causou má interpretação, muito difundida, na qual o filósofo grego parece afirmar que as histórias devem começar no começo. Dessa maneira, estudiosos renomados, como Wallace Martin (1991, p. 84, tradução nossa), afirmam que se pode "citar outra autoridade clássica, Horácio, que diz que épicos devem começar in medias res, no meio das coisas. [...] Embora pareça óbvio que narrativas devam acabar assim que o conflito principal terminar, tal fechamento é raro [...]".

Sternberg (1992, p. 481, tradução nossa), então, desembaraça a querela: "são os todos aristotélicos que 'começam no começo', não as tramas, que podem começar em qualquer tempo e, idealmente, num ponto posterior ao início cronológico, no interesse da complexidade e da compacidade". Antes de nos movermos mais distantes do começo deste texto, numa brevíssima divagação explanatória, cabe explicar que a afirmação de Martin (1991) sobre o fechamento se refere à lógica proporcional. Se é admissível que a história comece no começo, deve-se esperar que termine no fim. Ocorre que o fim é divisível entre o clímax e a resolução. A primeira, afirma Mckee $^{2}$ (2006, p. 295), é a promessa de uma emoção, pela qual se deve entregar "ao público a experiência que prometemos, mas não da maneira esperada [...] (o clímax deve parecer) inevitável e satisfatório". Já a segunda é "qualquer material deixado após o Clímax [...] (onde, por exemplo se pode) mostrar o alastramento dos efeitos climáticos" (Ibid., p. 296-7). Em outras palavras, as histórias terminam quando a resolução termina e esse término é arbitrariamente decidido pelo autor. Sucede que, entretanto, também a noção de arbitrário possa ser discutida. E, com isso, nosso argumento volta ao eixo: o todo não é tudo ou qualquer coisa. Aristóteles

Na tradução para o português de Eudoro de Sousa.

2 Robert Mckee, Christopher Vogler e Joseph Campbell possuem livros, já considerados clássicos, que são comumente utilizados como manuais da indústria audiovisual, despretensiosos enquanto filosofia ou resposta transcendente e desprestigiados pela academia, porém excelentes em relação ao didatismo com os quais lidam com as questões básicas da matéria da narratologia. 
(§ 43 do capítulo VII) esclarece que "É necessário, portanto, que os mitos bem compostos não comecem nem terminem ao acaso [...]", pois

\begin{abstract}
[...] Homero, assim como se distingue em tudo o mais, também parece ter visto bem, fosse por arte ou por engenho natural, pois ao compor a Odisseia não poetou todos os sucessos da vida de Ulisses, por exemplo, o ter sido ferido no Parnaso e o simular-se louco no momento em que se reuniu o exército. [...] o mito, porque é imitação de acções, deve imitar as que sejam unas e completas, e todos os acontecimentos se devem suceder em conexão tal que, uma vez suprimido ou deslocado um deles, também se confunda ou mude a ordem do todo. Pois não faz parte de um todo o que, quer seja quer não seja, não altera esse todo (§ 48 e 49 do capítulo VIII, grifo nosso).
\end{abstract}

Esse é o ponto fulcral desta seção do texto. Na narrativa, diversamente daquilo que se passa na matemática, a ordem dos fatores deveras impacta o produto, assim como a eleição de um recorte que contenha a ação a ser imitada num amálgama coerente. Tal amálgama é a expressão do todo aristotélico, categoria renomeada pelos formalistas russos para fábula, cuja definição é a "ação corporificada como uma cadeia de eventos cronológica, regida pela lógica da causa e consequência, que ocorre dentro de duração e espaço determinados" (BORDWELL, 1985, p. 49, tradução nossa). Em suma, a fábula (ou todo ou, mais corriqueiro, história) é o conjunto de causas e efeitos que começa pelo começo (uma causa cuja causa não tenha relevância para essa história) e termina pelo fim (uma resolução que ocorra após o clímax, quando nada mais possa afetar diretamente a emoção/efeito causada(o) pela história). A fábula/história de Dom Casmurro é composta por todos os acontecimentos narrados por Bentinho desde sua mocidade até o tempo atual da narração, no qual rememora os eventos que lhe ocorreram. Dessa forma, o livro cumpre o desígnio que o narrador mesmo se impõe, de "atar as duas pontas da vida, e restaurar na velhice a adolescência. Pois, senhor, não consegui recompor o que foi nem o que fui" (ASSIS, 1899, p. 5). Tudo aquilo que esteja relacionado à maneira do contar, ao modo que o narrador encontra para agregar pertinência à sua história - que deve ser reconhecida como "una e completa"3-, é parte da trama: "O syuzhet (geralmente traduzido como 'trama') é o arranjo e apresentação real da fábula [...]. O syuzhet é um sistema porque organiza componentes - os eventos da história e estados de coisas - de acordo com princípios específicos" (BORDWELL, 1985, p. 50, tradução nossa). O arranjo de Dom Casmurro pode sofrer diversos tipos de escrutínio analítico. Superficialmente,

3 m narratologia, nomeia-se tal efeito como isotopia. Salvatore Attardo (1994, p. 69, tradução nossa) explica que se supõe "que um texto tenha uma 'totalidade de significado' - em outras palavras, signifique algo como um todo. As isotopias são introduzidas como ferramentas de desambiguação [...]. A unidade de significado do texto pode ser obtida na seleção de um significado (uma leitura) que seja compatível com todos os elementos, isto é, a isotopia do texto, entre os vários significados dos elementos que compõem o texto". Dessa maneira, a isotopia se efetua quando o leitor encontra, ao longo de sua relação com o texto, a lógica que cimenta os elementos narrativos outrora aparentemente dispersos. 
por exemplo: em termos temporais, pode-se afirmar que ele é desordenado - do final para o começo e, então, para o meio; em termos de tipo de narrador, de primeira pessoa e aberto - que deixa claro suas interpretações, comentários ou julgamentos ${ }^{4}$.

A trama é a soma das estratégias que fazem o entremeio entre aquilo que se conta e o como o que se conta é contado. Outrossim, Guimarães Rosa (1994, p. 85, grifo nosso) nos deleita ao pôr em Grande Sertão: Veredas o seguinte enunciado: "O senhor vá pondo seu perceber. A gente vive repetido, o repetido, e, escorregável, num mim minuto, já está empurrado noutro galho. [...] Digo: o real não está na saída nem na chegada: ele se dispõe para a gente é no meio da travessia" . Saltando entre repetir e escorregar em meio aos sentidos possíveis, vamos procedendo nossa interpretação ao longo da leitura/travessia. O que nos apresenta Guimarães Rosa é virtualmente idêntico ao que os pesquisadores chamam de isotopia (ver nota 4, acima). Em outras palavras, a isotopia é uma junção de efeitos que operam, sobre os elementos perfilados pela trama em sua travessia, afinal, uma compreensão coerente do propósito da história. Logo, a afirmação de Aristóteles de que "não faz parte de um todo o que, quer seja quer não seja, não altera esse todo" se revela fundamental, vez que os efeitos estéticos do texto se manifestam à disposição de seu modo de apresentação ${ }^{5}$. É aqui onde está o coração, o centro nevrálgico, da força da narratividade.

A organização do tempo e o modo de fazer congruente o elo entre causas e efeitos nesse mesmo tempo depõem a favor do poder estético evocativo que a narrativa traz consigo: o segredo reside na maneira da travessia, ou seja, do conhecer. Tais sobressaltos são chamados de peripécia, por Aristóteles, que Ihes confere alto grau de narratividade ${ }^{6}$ e cujo funcionamento se efetua no "'reconhecimento', como indica o próprio significado da palavra, é a passagem do ignorar ao conhecer [...] o reconhecimento com peripécia ${ }^{7}$ suscitará terror e piedade, e nós mostramos que a tragédia é imitação de acções que despertam tais sentimentos" ( $\$ 61$ e 62 do capítulo X).

Passemos, dessa maneira, ao comentário dos modos de cooperação textual do leitor, nos termos de Eco, considerando o estimulado que recebera para a reconstituir os tempos das tramas numa história cognoscível e, ao longo desse percurso, quem responderá emocionalmente a essa mesma empreitada estética.

4 Na outra extremidade haveria o narrador encoberto: que não se apresenta no sentido de não emitir pistas sobre as próprias opiniões. Das muitas classificações existentes dos tipos de narrador, atenho-me neste momento àquela utilizada por Mieke Bal (2009). Cf. o oitavo capítulo da segunda parte para maiores detalhes.

5 Àqueles que disporem de certas capacidades, linguísticas ou enciclopédicas por exemplo, de proceder com a travessia. Traduzindo em termos de Umberto Eco, cujas teorias serão comentadas em breve: é necessário que o leitor modelo disponha de meios para encontrar as estratégias figuradas no autor modelo.

6 Para Meir Sternberg (1992, p. 499, tradução nossa), essa afirmação gerou uma tendência de desvalorização das narrativas ordenadas: "o fato de que Aristóteles atribuiu uma função distinta ao enredo complexo (surpresa, intensificação de piedade e medo), mas nada ao simples (rebaixado por falta de valor surpresa) revela que ele não tem uma teoria geral do efeito do enredo -enredo no trabalho como tal, daí da narrativa e narratividade propriamente". Sternberg afirma que as narrativas ordenadas têm o valor do crescente da tensão "no movimento inexorável em direção à catástrofe" (Ibid. p. 484).

7 A definição de peripécia se encontra no $\$ 56$ do capítulo IX: "é a mutação dos sucessos no contrário". Ou seja, alterações na trama que surgem no inverso da expectativa. 


\title{
Cooperações textuais, do autor modelo ao leitor modelo
}

Umberto Eco (2015, p. 89) explica que “a interpretação cabível é viabilizada por um recurso - sempre conjectural - ao topic discursivo. [...] Naturalmente, decidir a respeito do que se está falando é uma aposta interpretativa. Mas, os contextos permitem tornar essa aposta menos aleatória [...]". Na frase hipotética "Ugo levantou da cama. Ana gosta de amoras", como poderíamos estabelecer o topic, o assunto desse texto? Teríamos incrível dificuldade e precisaríamos remendar muitas brechas. Se, no entanto, o conjunto textual diz que "Ugo levantou da cama. Ana não mais estava", presumimos imediatamente um topic relacionado à ideia de relacionamento ou, quiçá, problema no relacionamento. Se as frases fossem "Ugo levantou da cama. Ana gosta de amoras. Ana lembrou de Ugo ao sentir o cheiro das amoras", assumiríamos que ambos possuem algum tipo de relação indefinida - de amizade, sexual ou familiar.

\begin{abstract}
No meu entendimento de conexão narrativa, os eventos anteriores levantam certas possibilidades, em vez de outras. Eles, por assim dizer, abrem uma gama de possibilidades sobre o que pode acontecer a seguir. Do ponto de vista do leitor, espectador ou ouvinte, trata-se de encorajar uma série de expectativas. Seguir uma história envolve ter uma noção ampla de seu destino - uma noção ampla do que pode acontecer a seguir - em vez de ter uma noção definitiva do que acontecerá a seguir [...]. Quando os eventos posteriores chegam na narrativa, o público acha-os inteligíveis apenas porque eles concordam ou caem no leque de possibilidades sugeridas pelos eventos anteriores da história (CARROLL, 2003, p. 130, tradução nossa).
\end{abstract}

Na soma de proposições maiores - do acúmulo das frases de um texto ou das imagens de uma obra audiovisual -, as gamas de possibilidades citadas por Carroll (2003), que perfazem aquilo que Aristóteles considerava digno de se poetar em cada caso, precisam rumar delineadas pela coerência causal da evolução dos atos. Nesse jogo, caso a intenção seja direcionar emoções, fazê-las brotar na fruição do ato da leitura, não bastará, todavia, a mera geração de conexões pertinentes. É preciso respeitar o espaço de movimentação do leitor.

Gustavo surge no décimo-primeiro episódio da segunda temporada de Breaking Bad ${ }^{8}$, nomeado de Mandala, mas não temos, ainda, qualquer indicação que esclareça o porquê e o como de sua calma, que, de tão extremada, inquieta. O leitor mais atento poderá supor que se trata de ódio enrustido, porém as confirmações de sua suspeita somente lhe serão legadas em Hermanos, oitavo episódio da quarta temporada, 23 capítulos e quase três anos depois. Antes de adentrar nesta análise, cabe asseverar que a dinâmica da leitura de narrativas se concretiza, na generalidade, por lacunas/espaços vazios. Isso pois "[...] o texto é uma máquina preguiçosa que espera muita colaboração da parte do leitor"

8 Deste ponto em diante do texto, por razões de sintetismo, citaremos como BB. 
(ECO, 2009, p. 34, grifo nosso). No texto "Ugo levantou da cama. Ana gosta de amoras. Ana lembrou de Ugo ao sentir o cheiro das amoras. Ugo chorou por todas as vezes que fez Ana sofrer", os espaços vazios continuam a reinar, apesar de o texto trazer, enfim, a confirmação de uma relação entre os dois. Porém, ainda vigora a dúvida: de que tipo? Contatos de amizade, sexual ou familiar, todos caberiam nesse exemplo - ainda que a conotação sexual pareça a opção mais coerente.

Mas o que faz de algo uma história? E o que torna uma história inteligível? [...] (as) pessoas executam operações em uma história. Quando a informação está faltando, os percebedores ${ }^{9}$ a inferem ou fazem suposições sobre ela. Quando os eventos são organizados fora da ordem temporal, os percebedores tentam colocar esses eventos em sequência. E as pessoas buscam conexões causais entre os eventos, tanto antecipadamente quanto retrospectivamente (BORDWELL, 1985, p. 33-4, tradução e grifo nosso).

O lugar vazio pluraliza as capacidades de ingerência do leitor, já entretido com o ordenamento dos tempos cronológicos e a seleção das importâncias relativas dos atos - gerando categorias não estanques do que é mais saliente e do que deve ser minorado na atenção, na interpretação e, por conseguinte, na memória. Dessa forma

[...] os lugares vazios não só fazem parte do repertório, mas também das estratégias. Sendo construção perspectivística, o texto demanda a interelação incessante de suas perspectivas. Visto que essas perspectivas formam camadas na construção textual, a leitura deve produzir constantemente a relação entre os diversos segmentos de uma mesma perspectiva e entre os segmentos de diversas perspectivas. Com frequência, os segmentos se justapõem. E essa técnica não só é usada por (James) Joyce ou pela literatura moderna, cuja narração segmentada aumenta o número de lugares vazios a tal ponto que a falta de conexões começa a desnortear a formação de representações empreendida pelo leitor (ISER, 1999, p. 129).

Por essa razão, é necessário orquestrar as operações do leitor, a fim de que caminhe pela coerência pretendida, vez que "gerar um texto significa aplicar uma estratégia que inclui as previsões dos movimentos do outro; como ocorre, em geral, em toda estratégia" (ECO, 1993, p. 79, tradução e grifo nosso). Quem gesta esse movimento é uma entidade aparte do autor empírico, que Umberto Eco (2015, p. 93) nomeia de autor modelo: "não estou especulando sobre as intenções do autor (real, empírico), mas sobre a intenção do texto, ou sobre a intenção daquele Autor-Modelo que estou em condições de reconhecer em termos de estratégia textual". A estratégia textual ou autor modelo é uma interface de conjunções que atua entre o autor empírico, pessoa com existência real e desejos infinitos para além do que consta na obra, e o ato de narração, concretizado por meio da figura

9 Teóricos de cunho cognitivista preferem usar tal termo em vez de leitor ou espectador, para enfatizar que se trata de um percepto de uma experiência física e mental. 
retórica do narrador que se exprime na obra. É por essa razão que a visão de mundo impregnada numa narrativa, denominada ótica pela professora Maria Lúcia Dal Farra (1978, p. 24, grifo da autora), dar-se-á "entre o ponto de vista do narrador - que pode percorrer toda a hierarquia das visões, desde a onisciência até o foco mais restrito - e os pontos de cegueira do narrador — os diferentes proveitos que o autor-implícito ${ }^{10}$ puder tirar daquilo que é vedado à sua máscara". Como poderia ser cego aquele que detém o conhecimento daquilo que conta?

Mais uma vez, Dom Casmurro proverá sinteticamente uma análise de interesse para a questão. Ao longo da obra de Machado de Assis, testemunhamos o desenrolar dos fatos enredados nas "duas pontas" da vida de Bentinho. Ordenamos esses acontecimentos, fazemos apostas sobre o que foi declarado e o que será, nos envolvemos empaticamente com seus relatos. Ao fim, somos deixados sem resposta definitiva: afinal, Capitu traiu Bentinho ou não? Toda a construção nos leva a crer que sim, até que a reflexão a posteriori nos permite verificar que a resposta "sim" está atrelada à aceitação incondicional da estratégia do autor modelo. A saber, o autor modelo provê uma única visão dos fatos, a de Bentinho. Uma única visão, macerada pela úlcera e distância no tempo, uma única visão maculada pelo ressentimento e autocomiseração de um indivíduo odioso, magoado e, portanto, parcial em seu julgamento. O narrador de Dom Casmurro, por conseguinte, é cego para outras versões, posto que apaixonado por sua própria opinião dos fatos. Dito de outro modo, a lacuna fundante da obra é aquilo que promove sua própria força poética, cujos efeitos se estenderam sobre os anos e elevaram Dom Casmurro ao panteão das obras primas da literatura mundial. Retomando Eco, o outro, cujos movimentos devem ser influenciados, é o leitor. Todavia, não se trata do leitor empírico - dos conjuntos reais de pessoas que lerão a obra. $\mathrm{O}$ autor modelo monta sua estratégia, com seus pontos intencionais de vistas e cegueiras, para o leitor modelo.

O texto, segundo Eco, é um mecanismo que, ao apresentar uma série de expressões ao leitor, o incentiva a concretizar diversos pressupostos. Normalmente, um texto é estruturado de forma a prefigurar as ações interpretativas de seu receptor e estimula a formulação de certas hipóteses em vez de outras. [...] O autor estrutura o texto de acordo com esse tipo de leitor em mente, com o objetivo de encontrar um equilíbrio entre o que o autor acha que deve ser explicitamente declarado e a informação que pode ser facilmente tomada como óbvia, já que se espera que ela faça parte do conhecimento enciclopédico do leitor pretendido (PISANTY, 2015, p. 44, tradução nossa e grifo nosso)

Ao longo do ato de leitura, somos livres para postular o que quer que seja enquanto leitores empíricos. Eco (2015, p. 89-90) nomeia uso esse ato, em contraste com a interpretação, que prevê que nos atemos às rédeas isotópicas, leia-se de coerência, que

10 Autor implícito e autor modelo são termos equivalentes. Também é possível encontrar o termo autor ideal em alguns textos. 
o autor modelo propõe ao leitor modelo. Afinal, o "'era uma vez havia três porquinhos' nos demanda questionar 'e o que aconteceu com eles?' e não 'por que três?' ou 'qual o contexto histórico concreto?'” (CULLER, 1992, p. 114, tradução nossa). O leitor modelo se move por entre as armadilhas do autor modelo e nelas encontra deleite. Para fazê-lo, precisa trazer hipóteses ao texto que advêm de conhecimentos de fora do texto. Assim, é evidente que o limite isotópico prevê dimensões para além de si mesmo. Não poderia haver coerência ou sequer conexão entre frases se o sujeito leitor não possui letramento na língua de expressão. Aquele que não compreende russo encontraria, num original de Dostoiévski, nada além de grandes conjuntos de letras organizadas de forma ilógica. Por essa razão, a noção de enciclopédia se faz tão cara para Eco (2015, p. 92-3): "a enciclopédia (é aquilo) que se constituiu mediante o exercício daquela língua, isto é, as convenções culturais que aquela língua produziu e a história das precedentes interpretações de muitos textos [...]". Ao balancear nossas apostas contra aquilo que o texto nos permite, usamos igualmente conhecimentos extralinguísticos ${ }^{11}$ que nos permitam validar o mundo da narrativa.

[...] a antecipação narrativa é uma questão de formar expectativas com base no grau de exequibilidade dos eventos, em função dos eventos anteriores da história. De onde surgem essas expectativas? Muitos lugares, incluindo nosso conhecimento do mundo [...], nosso conhecimento do que é possível dentro das convenções de um certo gênero narrativo, e nosso conhecimento do que é pensado possível, considerando as crenças da cultura em que a narrativa é composta (CARROLL, 2003, p. 132, tradução nossa).

Diferente da corrente mais usual, na qual gângsteres e traficantes são representados como pessoas com irrupções de raiva, descontrole, ataques passionais, fortes traços psicóticos, reapresentados por Hollywood ${ }^{12}$ diversas vezes, poderíamos citar a singela eloquência de Don Corleone em O Poderoso Chefão (EUA, 1972, dir.: Francis Ford Coppola) ou a quase passividade de Gustavo Fring em BB. Giancarlo Esposito, seu intérprete, ao ser questionado sobre o esboço do personagem feito para ele pelos produtores, afirmou: "Em sua descrição, ele era um cara que era muito admirável, muito educado, o gerente do restaurante. E eu queria sê-lo muito, muito calmo e muito relaxado, mas eu queria que ele fosse alguém que tivesse algum tipo de segredo"

11 É notável e medível a diferença que o conhecimento sobre o tema da narrativa exerce sobre a interpretação dos leitores empíricos, no quanto eles são capazes de seguir o autor modelo em sua prescrição ao leitor modelo. Dessa maneira, Richard Gerrig inicia sua explicação de como os atos de memória e atenção se delineiam nos textos, segundo estudo realizado a partir do acompanhamento da narração de um jogo de beisebol. Assim, "(J. F.) Voss e seus colegas examinaram o desempenho de indivíduos com baixo ou alto conhecimento de beisebol, um domínio escolhido por causa de suas metas e ações ricamente estruturadas. No geral, esses experimentos demonstraram que os ricos ficam mais ricos [...] indivíduos de alto conhecimento se lembravam de detalhes relevantes para o resultado do jogo com maior frequência, como o progresso de determinados corredores. Os sujeitos de baixo conhecimento eram mais propensos a agir como se estivessem lembrando de fatos não relacionados e exibiam maior apego apenas a detalhes sem importância, como nomes de jogadores (1998, p. 41, tradução e grifo nosso).

12 Um exemplo marcante é o de Tony Camonte/Montana nas versões cinematográficas de Scarface (EUA, 1932 e 1983, dir.: Howard Hawks e Brian De Palma). 
(PONIEWOZIK, 2011, tradução e grifo nosso). Por não termos o quadro completo daquilo que ocorreu com Gustavo, no momento da exibição de Mandala, por exemplo, resta a nós fruir os tempos da trama como eles nos são legados e, então, inferir ou apostar na maneira que os dados apresentados se conformarão num todo coeso e impactante. Enquanto coparticipantes da narrativa, agimos sobre os espaços vazios (qual acontecimento pregresso levou Gustavo a ser/atuar dessa maneira na atualidade?) influenciados pelas possibilidades que texto abre e/ou fecha a cada momento de sua apresentação. Podemos apostar, por exemplo, que aquela fineza gestual e vocal e sua impassibilidade monástica, na verdade, são a vazão do preciso inverso. Ou seja, pura premeditação e cálculo deliberatório que se finca sobre algo desconhecido. E o leitor empírico que tenha seguido o autor modelo em seu guião enciclopédico sobre o leitor modelo encontrará nessa lacuna - o que se passou com ele? -, a concretização de um elo de empatia e emotividade com Gustavo.

Numa data longínqua, os anacronismos entrarão em eixo e a atividade de cooperação do leitor será inteiramente recompensada. Trata-se do supracitado episódio Hermanos, no qual ocorre uma espécie de confirmação das hipóteses sobre as quais já deblaterávamos na travessia da narrativa.

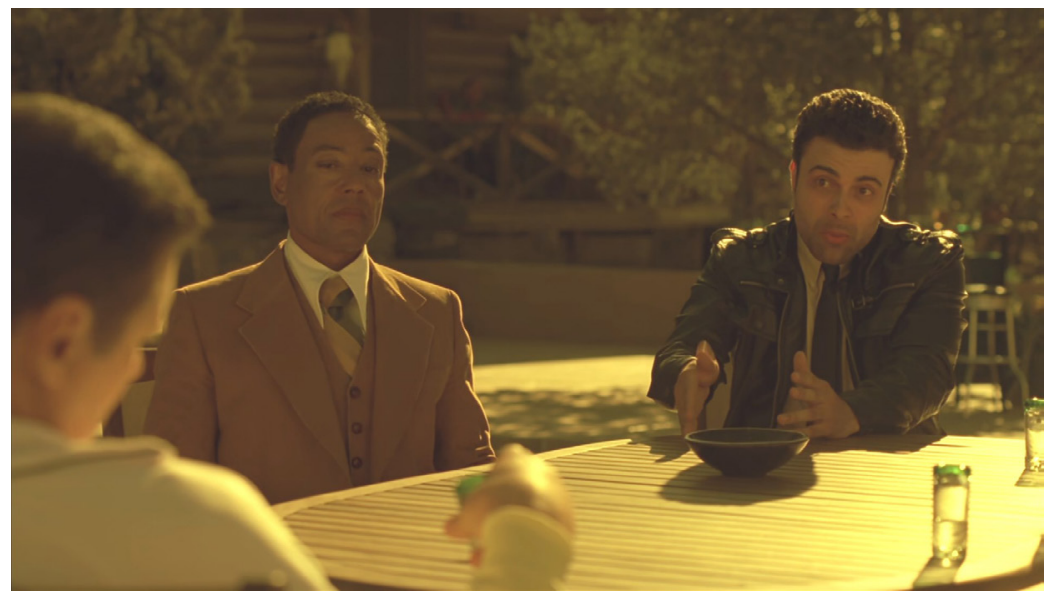

Fig. 1. Em Hermanos, Don Eladio (à esquerda), Gustavo (centro) e Max (direita)

No tempo atual do seriado, 2008-09, Don Eladio Vuente (Steven Bauer) é o líder do cartel mexicano Juárez-Michoacan. Ele comanda, entre outros, dois grandes distribuidores nos EUA: Hector Salamanca (Mark Margolis) e Gustavo Fring, que competem entre si pelo controle do território. A animosidade entre Hector e Gustavo é elemento constante no seriado, sendo alocada pouco a pouco na tela e, geralmente, de forma sutil, assim como as pouquíssimas menções diretas, sempre atemorizantes, ao nome de Eladio. Em Hermanos, saímos do tempo atual da ação, num flahback que ocorre em 1989, aproximadamente vinte anos antes dos eventos de BB, quando um jovem Gustavo chega à portentosa hacienda de Eladio, acompanhado de seu parceiro Max Arciniega (James Martinez). 
Gustavo e Max possuem uma relação não inteiramente especificada, sobre a qual a narrativa - nesse caso: olhares, gestos - emite sinais que possibilitam a leitura de uma interação romântica. Com muito orgulho de quem apresenta como seu protegido e parceiro de negócios (o restaurante Los Pollos Hermanos), Gustavo anuncia para Eladio que havia pagado todos os estudos de Max, numa formação em Engenharia Química, o que o habilitaria a produzir drogas diretamente em território estadunidense, evitando, assim, todos os riscos da operação que trazia o produto da Colômbia até o cartel no México e, depois, rumo aos EUA.

Nesse momento, Eladio se irrita e Max se amedronta por Gustavo. Max diz: "Ele é meu parceiro! Eu preciso dele", alguns segundos antes de Hector Salamanca se aproximar dos três e atirar, fatalmente, em Max. Hector, então, prende Gustavo contra o chão, obrigando-o a ver seu companheiro sangrar até a morte.

Eis o segredo de Gustavo, outrora lacuna, agora recuperada pela trama. O texto informa explicitamente, desse modo, que a calma de Gustavo escondia sua dor e que sua atitude era, deveras, calculista. Afinal, como afirma Carroll, afinamos a isotopia da narrativa com nosso conhecimento de mundo. Nesse sentido, poderíamos questionar: quem conseguiria trabalhar para Eladio e ao lado de Hector, por vinte anos, após tal fato? Gustavo, ainda que colérico e vingativo, agiu com parcimônia, conforme sua natureza, e aguardou os melhores momentos para se vingar de ambos ${ }^{13}$. O autor modelo já havia nos alertado, em muitíssimos sinais que se acumularam ao longo das temporadas, claros ao leitor modelo, de que nessa lacuna específica não poderia haver outra coisa além de negatividade e dor, cuja força centrípeta agiu como impulso destrutivo que condenou a vida de todos os envolvidos a mais malquerença e mais hostilidade, num perpétuo e circular ato de break bad ${ }^{14}$ sobre seus próprios futuros.

Wanderley Anchieta é doutorando no Programa de Pósgraduação em Comunicação da Universidade Federal Fluminense.

wya@outlook.com

\section{Referências}

ARISTÓTELES. Poética [tradução de Eudoro de Sousa]. Lisboa: INCM, 2003.

ASSIS, M. Dom Casmurro. Rio de Janeiro: H. Garnier, 1899.

ATTARDO, S. Linguistic Theories of Humor. Nova lorque: Mounton de Gruyter, 1994.

13 De Don Eladio, em BB, no décimo episódio da quarta temporada, intitulado ironicamente de Salud. De Hector, haverá revelação somente no spin off intitulado Better Call Saul.

14 Em inglês, trata-se de uma expressão coloquial que significa, entre outras coisas: partir para a violência momentânea, cometer crimes etc. 
BAL, M. Introduction to the theory of narrative. Toronto: University of Toronto Press, 2009.

BORDWELL, David. Narration in the fiction film. Wisconsin: The University of Wisconsin Press, 1985.

BUARQUE, C. Budapeste: romance. São Paulo: Companhia das Letras, 2016.

CARROLL, N. Beyond Aesthetics: philosophical essays. Nova York: Cambridge University Press, 2003.

CULLER, J. In defence of overinterpretation. In: ECO, U.; COLLINI, S. (orgs). Interpretation and overinterpretation. Cambridge: Cambridge Press, 1992.

DAL FARRA, M. L. O narrador Ensimesmado. São Paulo: Editora Ática, 1978.

ECO, U. Lector in Fabula: la cooperación interpretativa en el texto narrativo. Cambridge: Lumen, 1993. Seis passeios pelo bosque da ficção. São Paulo: Companhia das Letras, 2009.

Os limites da interpretação. São Paulo: Perspectiva, 2015.

GENETTE, G. Discurso da Narrativa. Lisboa: Vega, 1995.

GERRIG, R. J. Experiencing Narrative Worlds - on the psychological activities of reading. Colorado: Yale University Press, 1998.

ISER, W. O ato da leitura - uma teoria do efeito estético (vol. 2). São Paulo: Editora 34, 1999.

MARTIN, W. Recent theories of narrative. Ithaca: Cornell University Press, 1991.

PISANTY, V. From the model reader to the limits of interpretation. In: Semiotica, 206. Publicado em 2015. Disponível em < https://bit.ly/2PBEOKD > . Acesso em 07.05.18.

PONIEWOZIK, J. Interview: Talking Gus Fring with Giancarlo Esposito. Disponível em < https://ti.me/2yytMEj >. Acesso em 19.09.18.

ROSA, G. Grande Sertão: Veredas. São Paulo: Nova Aguilar, 1994.

STERnBerG, M. Telling in Time (II): Chronology, Teleology, Narrativity. In: Poetics Today, vol. 13, n. 3. Publicado em 1992. Disponível em < https://bit.ly/2NQCbvB >. Acesso em 07.05.18. 